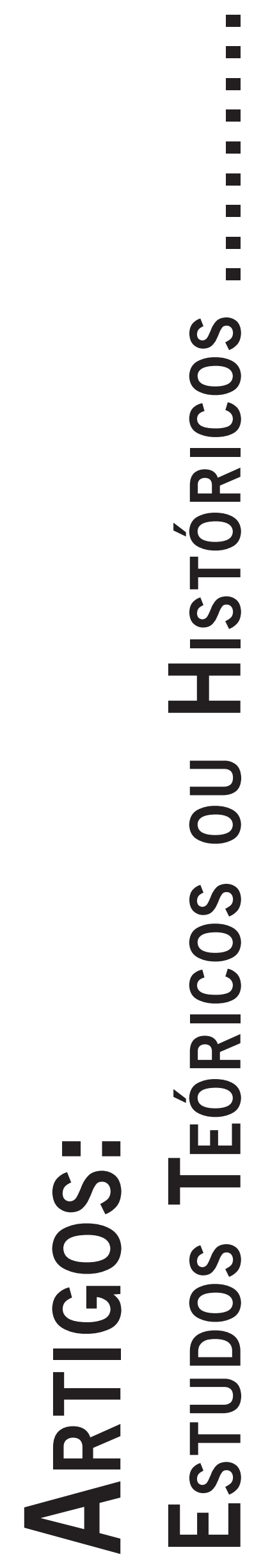




\title{
INTENCIONALIDADE E COMPORTAMENTO: A PERCEPÇÃO VIVENTE EM MERLEAU-PONTY
}

\author{
Intentionality and Behavior: the Living Being Perception in Merleau-Ponty
}

Intencionalidad e Comportamiento: la Percepcion Viviente em Merleau-Ponty

Pedro Henrique Santos Decanini Marangoni

DANILO SARETTA Verissimo

\begin{abstract}
Resumo: Nos trabalhos iniciais de Merleau-Ponty, a percepção é definida como tema específico de investigação, posto que, para o filósofo, ela se encontra na junção do sujeito e das suas condições orgânicas de vida. Em A estrutura do comportamento, seu primeiro livro, Merleau-Ponty realiza estudos acerca do sujeito perceptivo considerado do exterior, daí a importância que adquirem, para o autor, a noção de comportamento e as pesquisas experimentais da psicologia animal e da psicopatologia. Na obra, o problema do organismo e da animalidade é reescrito mediante a refutação da construção científica da realidade biológica. O pensamento estrutural permite a Merleau-Ponty tratar o campo de percepção animal a partir de um registro intencional, fruto de uma concepção dialética, e não causal do comportamento. Com base nas discussões entabuladas por Merleau-Ponty em A estrutura do comportamento, contamos evidenciar os elementos fundamentais de interpretação da percepção animal em termos de intencionalidade. Definir o comportamento em um registro intencional significa afirmar que a atividade orgânica é instituinte e significativa. É através da ação, pautada por normas vitais, que o organismo instaura um meio significativo para si.
\end{abstract}

Palavras-chave: Merleau-Ponty; comportamento; intencionalidade; organismo.

\begin{abstract}
In the early works of Merleau-Ponty, perception is defined as a specific research topic, since, for the philosopher, it is at the junction of the subject and its basic living conditions. In The Structure of Behavior, his first book, Merleau-Ponty performs studies on the perceiving subject considered from outside, hence the importance that acquire, for the author, the notion of behavior and the experimental studies of animal psychology and psychopathology. In the work, the problem of the body and animality is rewritten by the refutation of the scientific construction of the biological reality according to structuralist biology and psychology. Structural thinking allows Merleau-Ponty to treat the animal's perception field from an intentional record, the result of a dialectical, not causal, conception of behavior. Based on discussions made by Merleau-Ponty in The Structure of Behavior, we highlight the key elements of interpretation of animal perception in terms of intentionality. Define the behavior of an intentional record mean to say that organic agriculture is instituting and meaningful. It is through action, guided by vital norms that the body establishes a significant means for you.
\end{abstract}

Keywords: Merleau-Ponty; perception; behavior; intentionality; organism.

Resumen: En los primeros trabajos de Merleau-Ponty, la percepción es definida como un tema de investigación específica, ya que, para el filósofo, ella se encuentra en la unión del sujeto y de sus condiciones orgánicas de vida. En La estructura del comportamiento, su primer libro, Merleau-Ponty realiza estudios acerca del sujeto perceptor considerado del exterior, de ahí la importancia que adquieren, para el autor, el concepto de comportamiento y los estudios experimentales de la psicología animal y de la psicopatología. En la obra, el problema del cuerpo y la animalidad es reescrito por medio de la refutación de la construcción científica de la realidad biológica. El pensamiento estructural permite Merleau-Ponty tratar el campo de la percepción animal a partir de un registro intencional, resultado de una concepción dialéctica e no causal del comportamiento. Con base en las discusiones elaboradas por Merleau-Ponty en La estructura del comportamiento, podemos destacar los elementos clave de la interpretación de la percepción animal en términos de intencionalidad. Definir el comportamiento en un registro intencional significa decir que la actividad orgánica es creadora y significativa. Es a través de la acción, guiada por normas vitales que el organismo establece un medio significativo para si mismo.

Palabras-clave: Merleau-Ponty; comportamiento; intencionalidad; organismo.

\section{Introdução}

O conceito de intencionalidade não se encontra formalizado n'A Estrutura do Comportamento, primeiro livro de Merleau-Ponty (1942/2006). Vale considerar, inclusive, que referências incipientes a Husserl aparecem apenas no último capítulo da obra. Se não há, nesse trabalho, uma teoria explícita da intencionalidade vivente, nele são apresentados, por outro lado, importantes elementos que po- dem ser interpretados sob o prisma da intencionalidade. Esta é a nossa tese. Ao usarmos o termo intencionalidade estamos nos referindo, nesse contexto, a uma diretividade comportamental mediada, no caso dos animais, por processos gestálticos de seleção e atribuição de sentido. Merleau-Ponty, n'A estrutura do comportamento, reinterpreta o conceito, herdado da tradição fenomenológica, oferecendo uma nova via de análise calcada na ideia de Gestalt. Em sua acepção geral, a intencionalidade é uma 
propriedade de referência, isto é, ela diz respeito ao fato de que toda consciência é, essencialmente, voltada para o mundo. No âmbito da subjetividade vivente, a intencionalidade vital se caracteriza como a referência a metas ou a conjuntos de estímulos que são selecionados pelo organismo segundo suas normas internas.

Numa teoria do comportamento vivente comprometida com a dimensão intencional da experiência, entende-se que os organismos constituem seu próprio meio a partir de suas significações vitais. É através da ação, pautada por normas vitais, que o organismo instaura um meio próprio para si. A constituição ativa do ambiente a partir de suas próprias demandas nos indica que a essência de todo vivente é ser o centro de sua própria vida. Na primeira obra de Merleau-Ponty, o problema da intencionalidade segue os contornos das discussões realizadas sobre o comportamento em contraponto ao naturalismo científico.

Nosso propósito é, justamente, delinear considerações a respeito da intencionalidade na obra $A$ Estrutura do Comportamento, de Merleau-Ponty. Nosso objetivo principal consiste em evidenciar os elementos que, neste livro, apontam para uma teoria da intencionalidade vivente que não se restrinja à ordem humana. Para tanto, iniciamos a discussão mostrando como Merleau-Ponty contrapõe-se à antinomia clássica entre consciência e natureza ao propor um retorno à ideia de comportamento. Analisamos, brevemente, as conceitualizações da psicologia científica de então, a fim de evidenciar o movimento pelo qual Merleau-Ponty se distancia do mecanicismo ao inserir o organismo como sujeito da percepção. Enfatizamos, ademais, o percurso pelo qual Merleau-Ponty descreve a atividade vivente, imbuindo-se do conceito de forma, visando superar o mecanicismo vigente nas teorias comportamentais científicas. Ao final, nos deparamos com a questão da diferença antropológica, abordada por Merleau-Ponty através do conceito de multiplicidade perspectiva.

\section{Comportamento e naturalismo}

As primeiras obras de Merleau-Ponty, A Estrutura do Comportamento (1942/2006) e a Fenomenologia da Perсерс̧ão (1945), integram um mesmo programa filosófico, cujo tema central é o problema da percepção. Em seu livro de estreia, Merleau-Ponty esclarece que seu objetivo consiste em "compreender as relações entre a consciência e a natureza - orgânica, psicológica ou mesmo social” (1942/2006, p. 1). Trata-se, em outras palavras, de questionar as possibilidades de articulação entre o que é exteriormente dado, no sentido empírico do objeto exterior, e aquilo que é propriamente da esfera ideal, e que pertence ao reino da consciência (Moinat, 2012, p. 92). Com efeito, para o filósofo, nem a noção empírica de natureza nem tampouco a concepção filosófica de consciência, herdada de Descartes, são suficientes para se descrever a experiência perceptiva. Deparamo-nos, de um lado, com as explicações derivadas da filosofia transcendental, que enfatizam o estudo das estruturas formais da consciência, sendo consideradas "investigações reflexivas". A crítica de Merleau-Ponty dirige-se principalmente ao pensamento neokantiano (Ferraz, 2009). Para o neokantismo, "o mundo é o conjunto de relações objetivas sustentadas pela consciência” (Merleau-Ponty, 1942/2006, p. 1). A consciência, conforme esse campo teórico, relaciona-se apenas com o que fora estabelecido por suas propriedades cognitivas. As ciências que se apropriam deste pressuposto têm como característica a modulação da realidade conforme a escolha do modelo adotado. Por exemplo, "segundo um modelo físico mecânico, a realidade aparece como conjunto de partículas em movimento, segundo um modelo dinâmico, como um conjunto de forças em interação" (Ferraz, 2009, p. 22). Em outra perspectiva, em conformidade ao empirismo, as investigações pautadas pelos parâmetros das ciências naturais são chamadas de explicativas. Esta espécie de investigação tem como alicerce epistemológico o pensamento causal. Segundo esta ordem científica, considera-se que todo fenômeno pode ser explicado de acordo com as categorias de causa-efeito advindas da observação do mundo físico. No âmbito d'A Estrutura do Comportamento, este tipo de pensamento é representado pela psicologia científica, tendo-se como modelo principal a fisiologia de Pavlov.

Frente às posições do naturalismo científico e da filosofia reflexiva, devemos nos perguntar: por qual razão Merleau-Ponty (1942/2006) adota, como linha de análise dos problemas propostos, a noção de comportamento? De acordo com o filósofo, o comportamento, considerado por ele mesmo, é neutro em relação às distinções entre o fisiológico e o psíquico. O comportamento expressa o debate do agente com o meio físico e social. Foi no behaviorismo watsoniano, no contexto da negação da interioridade da consciência e do foco exclusivo no estudo fisiológico, que o comportamento foi definido como soma de reflexos naturais e condicionados. Merleau-Ponty mostra que a análise minuciosa da noção de comportamento possibilita a crítica à exterioridade do método científico do behaviorismo clássico. Evita-se, por outro lado, a imersão no ideário racionalista. Como ressalta Geraets (1971), ao se inserir a consciência como conceito-chave no estudo da percepção, assume-se o risco de impor a primazia da interioridade sobre o mundo percebido. Ante as definições fornecidas pelas ciências e pela filosofia reflexiva, a noção de comportamento adquire, sob a pena de Merleau-Ponty, o estatuto de "exigência metodológica", pois tal conceito resiste às apropriações polarizantes do pensamento causal ou do pensamento criticista. O comportamento, em sua neutralidade constitutiva, "permanece fiel aos dados fornecidos pela simples descrição” (Bimbenet, 2004, p. 38).

Neste sentido, A Estrutura do Comportamento afronta o naturalismo científico partindo de uma revisão dos conceitos que sustentam a exterioridade como princípio epistemológico. A descrição destes fundamentos anun- 
cia na prosa merleau-pontyana uma preocupação voltada para o tipo de ontologia que sustenta o naturalismo. No lugar de se ater somente aos fatos trazidos pela análise experimental, é preciso colocar em evidência que toda ciência pressupõe um fundo metafísico (Furlan, 2001). A própria evolução dos modelos científicos acarreta mudanças epistemológicas, de modo que é necessário que a análise filosófica se detenha em uma revisão dos pressupostos formulados pela ciência. $\mathrm{O}$ estabelecimento de uma ontologia naturalista, fundada em uma visão objetiva do Ser, implica a assunção, por parte do cientista, de uma determinada forma de compreender as "leis da natureza” (Merleau-Ponty, 1984, p. 227) e, por conseguinte, de formulá-las. Esta forma singular de organização da realidade baseia-se, especialmente, no pensamento causal.

Para Merleau-Ponty, a reflexão sobre a neutralidade do comportamento nos revela todo prejuízo metafísico que fora legitimado pelo pensamento causal. A causalidade tratada n'A Estrutura do Comportamento é, em seu cerne, realista. Postula-se que a realidade existe à parte do observador, de modo que os fenômenos seguem padrões causais e independentes do sujeito. Nesta perspectiva, como veremos mais a fundo, o comportamento e, logo, o organismo, são descritos como componentes de uma realidade considerada como uma soma de elementos independentes. Tal como um mosaico, figura geométrica na qual a organização do todo é dada pela relação isolada de cada parte entre si, a atitude naturalista adotada pela psicologia no estudo do comportamento considera que o entendimento da totalidade dos fenômenos demanda a investigação de cada parte isoladamente.

N'A Estrutura do Comportamento, as abordagens científicas que se propõem ao estudo experimental da conduta enfatizam o caráter determinante dos processos fisiológicos na dinâmica comportamental. O realismo assume, neste ponto, a forma do materialismo fisiológico, que define a consciência como determinação de fenômenos físicos e fisiológicos. Os representantes do realismo, aos quais se refere Merleau-Ponty, são o behaviorismo americano e a fisiologia de Pavlov. Vejamos brevemente as linhas gerais de tais programas.

Em seu célebre artigo, Psicologia como o Behaviorista $a$ vê, Watson (1913) estabelece que a coerência da pesquisa em psicologia só é alcançada mediante a exclusão de referências a estados subjetivos. Trata-se, em outras palavras, de eliminar do vocabulário behaviorista toda terminologia que insinue a investigação da consciência. A utilização de termos como percepção, imagem, sensação, pode subentender, segundo o behaviorista, o retorno à linguagem metafísica utilizada na psicologia introspeccionista. Para Watson, um dos méritos das ciências naturais reside no princípio de generalidade sob o qual deve se apoiar qualquer hipótese científica. A reprodução dos experimentos sob determinadas condições-chave deve resultar em dados equivalentes, independentemente das condições exteriores ao experimento. Isso possibilita uma maior aplicabilidade dos achados e, consequentemente, torna viável a sua discussão pelos pares. Segundo Watson (1930), a negação da consciência envolve uma busca por uniformidade metodológica.

Com este intuito, e ancorando-se na reflexologia pavloviana, Watson formula uma teoria do comportamento que torna possível o controle experimental e a generalização dos dados obtidos. O psicólogo americano define toda atividade comportamental em termos de estímulo e resposta. Para esta ciência do comportamento, o behaviorismo, o estímulo define-se como a propriedade ambiental de suscitar determinadas variações no organismo, sejam comportamentais ou fisiológicas (Watson, 1930). Qualquer objeto do entorno do organismo pode desempenhar o papel de estímulo. Por resposta Watson compreende toda atividade orgânica. Deste modo, ao invés de inferir processos mentais que regeriam a dinâmica comportamental, o behaviorismo propõe que toda resposta seja avaliada em termos dos estímulos ambientais.

Na teoria reflexológica de Pavlov, a atividade orgânica é explicada pelas propriedades absolutas do excitante, de forma que "é indispensável, em primeiro lugar, um agente externo que provoque a excitação" (Pavlov, 1917/1970, p. 187). A contração da pupila sob uma forte luz, a resposta defensiva frente às ameaças ambientais, a salivação intensa em contato com estímulos alimentares, representam exemplos de respostas fisiológicas precisas, determinadas por propriedades específicas dos estímulos. Pavlov (1917/1970) escreve: "Não há mais lugar para o acaso. Os fenômenos estão, novamente, ligados por relações causais" (p. 188). Lembremos que, para Merleau-Ponty (1942/2006), "uma ação mecânica, quer tomemos a palavra no sentido restrito quer no sentido amplo, é aquela em que a causa e o efeito são decomponíveis em elementos reais que se correspondem um a um” (p. 250). A eficácia de um determinado estímulo é averiguada segundo sua capacidade de "excitar", por meio de propriedades físico-químicas, um determinado receptor circunscrito. Fatores como o lugar da excitação, a intensidade do excitante e suas propriedades físico-químicas são determinantes na consecução da resposta. A reação representa, para a teoria clássica, o componente final do arco reflexo e, simboliza a parte eminentemente "ativa” do processo. Caracteriza-se a reação como o único tipo de atividade do organismo, o que implica considerar que a recepção dos estímulos exprime uma operação passiva. Em outros termos, segundo a teoria do reflexo, os processos sensório-motores são, em princípio, diferentes. Eles constituem-se como duas ordens de acontecimentos. Assim, ao se explicar a atividade reflexa como a soma de processos isolados, que se comunicam apenas de forma pontual, toda a reação do organismo a agentes externos permanece no âmbito da reatividade (Buytendijk, 1952, p. 200). Vejamos, a seguir, como Merleau-Ponty, por intermédio do conceito de forma, reformula a noção de comportamento e restabelece ao organismo seu papel de agente. 


\section{A noção de forma e a intencionalidade vivente}

A estratégia metodológica adotada por Merleau-Ponty consiste em aproximar-se do discurso científico visando trazer a lume as consequências filosóficas de se descrever o comportamento como objeto das ciências naturais. Merleau-Ponty recorre ao conceito de forma da escola alemã de Psicologia da Gestalt com o intuito de reformular o papel assumido pela consciência. Se, de um lado, a psicologia científica recorre à fragmentação como ferramenta de explicação dos fenômenos, por outro lado, a noção de forma revela que o campo perceptivo é originalmente estruturado, configurando-se como uma totalidade, cujo sentido é imanente à estruturação do campo. Isso significa que a experiência perceptiva não pode ser reduzida à soma dos elementos que compõem o mundo percebido. Diferentemente dos princípios atomistas que regem a fisiologia de Pavlov, uma organização gestáltica pressupõe que "cada momento é determinado pelo conjunto dos outros e seu valor respectivo depende de um estado de equilíbrio total" (Merleau-Ponty, 1942/2006, p. 144). A forma, diferente do elemento, é introduzida na descrição do mundo percebido sem pressupor nada que não possa ser encontrado no próprio mundo percebido. Recomenda-se, então, seguir "as articulações naturais dos fenômenos" (Merleau-Ponty, 1942/2006, p. 63). Deve-se, em outros termos, retomar a prioridade do mundo fenomenal e postular que a consciência, antes de assumir os modos de ser do cogito cartesiano, é, fundamentalmente, consciência perceptiva.

Para a Psicologia da Gestalt, o mundo que se doa para a consciência é primeiramente um mundo de conjuntos significativos e não de representações ou estímulos físicos, tal como postula a reflexologia pavloviana. No naturalismo científico, ademais, o aspecto fenomênico do corpo vivo é substituído pela análise detalhada dos processos moleculares que compõem a conduta. É necessário alterar, portanto, a própria noção de organismo, ou de ser-vivo, apresentada pelas ciências biológicas de orientação mecanicista. Diante das teorias que explicam a atividade orgânica recorrendo a pressupostos mecanicistas, ou, ainda, ante a ideia de que haveria uma força vital que animaria a matéria, a noção de forma permite descrever o organismo como "uma estrutura indecomponível de comportamentos" (Merleau-Ponty, 1942/2006, p. 67). Köhler (1929/1968), proeminente psicólogo da Gestalt, fornece um importante quadro das implicações assumidas pelo paradigma da forma:

Nosso ponto de vista será que, em vez de reagir aos estímulos locais por meio de fenômenos locais e mutuamente independentes, o organismo reage ao padrão de estímulos aos quais está exposto, e que esta reação é um processo unitário, um todo funcional, que oferece, na experiência, uma cena sensorial e não um mosaico de sensações locais. (p. 64)
No que concerne ao organismo, o que significa renunciar ao atomismo em prol da noção de forma? A alteração da perspectiva atomista para a semântica da forma permite reavaliar a função do estímulo como causa do comportamento. A excitação não é, desse modo, um processo isolado da própria atividade do organismo. Entre o conjunto de estímulos atuantes e a postura do organismo frente ao mundo percebido, as relações não são de exterioridade, mas de imbricação. Tal crítica não sugere, contudo, que a organização gestáltica exija a presença de algo como um aparelho psíquico. Computadores e instrumentos musicais são exemplos de máquinas que produzem infinitas combinações de respostas a depender da configuração dos excitantes enviados. Permanece, todavia, um questionamento: é válido afirmar que um organismo reage aos excitantes do mesmo modo como o instrumento responde aos comandos do pianista que o toca? Merleau-Ponty responde negativamente, pois o piano em-si não constrói a unidade melódica, que só é possível graças à performance do músico e à doação daquele que escuta. A coesão funcional da atividade vivente difere da lógica de um instrumento, sobretudo, porque o próprio organismo contribui na elaboração do ambiente externo. Este princípio é basilar na definição da atividade vivente como intencional. Se é inviável considerar o comportamento como um desdobramento de ações exteriores, é porque "o comportamento é a causa primeira de todas as estimulações” (Merleau-Ponty, 1942/2006, p. 14).

Não se trata de negar a dimensão físico-química dos fenômenos, e sim de superar a visão pela qual o estímulo seria equiparado a uma realidade física. Ao descrever a relação dos organismos com estímulos significativos, viabiliza-se o retorno ao campo biológico, no qual os excitantes são ocasiões, e não causas, para manifestação dos comportamentos. Nesta configuração, a relação entre estímulo e organismo passa a ser pautada por valores funcionais, que são prescritos de antemão pela própria situação orgânica e motora do vivente. Por exemplo: determinados organismos são mais sensíveis a Gestalten auditivas, enquanto outros embasam sua atividade, principalmente, em conjuntos visuais. Esta relação, que polariza certos conjuntos de estímulos em detrimento de outros, não se perfaz segundo a suposição de uma entidade interna que organizaria o sentido, tal como uma substância pensante, visto que o ambiente antecipa-se na atividade; ele é, para o animal, "o conjunto de coisas que interessam à sua ação” (Bimbenet, 2014, p. 104).

Façamos uma breve comparação. No âmbito dos fenômenos físicos, por exemplo, o equilíbrio dos sistemas pode ser definido a partir da interação entre as forças externas e as forças internas. Se tanto os sistemas físicos, quanto os sistemas vitais, estruturam-se em torno da noção de equilíbrio, qual seria a diferença fundamental entre um sistema físico e um sistema orgânico? Para Merleau-Ponty, os agentes externos desempenham funções distintas nos dois casos. Em um sistema físico, as forças externas inte- 
ragem segundo princípios de autodistribuição dinâmica que tendem a aproximá-lo de uma condição de equilíbrio de forças. Deste modo, as configurações possíveis de um sistema físico são engendradas a partir de condições presentes e reais, que cumprem o papel de estímulos regulatórios da organização interna (Merleau-Ponty, 1942/2006, p. 227). Nas estruturas orgânicas, por outro lado, o equilíbrio funcional não depende exclusivamente de processos de autodistribuição de forças. A singularidade de um organismo está em sua capacidade de apresentar comportamento, o que quer dizer que as condições de equilíbrio são criadas segundo as próprias normas vitais do organismo. A força externa não é uma entidade alheia ao sistema. O que se encontra fora do organismo só é constituído como objeto de atenção ou como força influente a partir das próprias normas ${ }^{1}$ internas que regulam a atividade sensível. Nessa direção, Ellis (2006) afirma: "Nós somos conscientes das informações aferentes apenas na medida em que nós ativamente 'prestamos atenção’ a elas, e este processo de direcionamento da atenção é motivado pelas necessidades do organismo” (p. 46, grifos do autor).

Estabelece-se, portanto, no caso dos organismos vivos, uma "intencionalidade de tipo funcional", que se efetiva como uma espécie de "compreensão vital do meio" (Bimbenet, 2004, p. 55). Com o intuito de destacar que a atividade vivente só pode ser compreendida como ação orientada e, portanto, dotada de sentido, fiamo-nos na ideia de que o estímulo considerado como acontecimento físico não é suficiente na descrição do comportamento. Por intencionalidade vital nos referimos, nesse contexto, à ideia de que os perceptos do animal são Gestalten com valores funcionais inerentes. A visada de um organismo ao mundo pode ser definida como intencional enquanto insere no ato mesmo de dirigir-se às coisas uma espécie de modulação do meio conforme significações vitais próprias. N'A Estrutura do Comportamento, a gênese dessa questão remete diretamente à distinção realizada por Koffka (1935/1975) entre meio comportamental e meio geográfico. Para este psicólogo da Gestalt, os espaços nos quais ocorrem as ações de um organismo não se limitam apenas à topografia geográfica das situações. A atividade não se desdobra somente em um ambiente físico. Os modos peculiares que cada organismo apresenta ao selecionar os estímulos ambientais constituem-se como níveis de ação que não são dedutíveis da relação do organismo com uma realidade substancial (Merleau-Ponty, 1942/2006, p. 202). Entre o meio geográfico e o comportamento, estabelece-se outro plano de ação, que é, sem dúvida, dependente do campo geográfico, mas que não se limita ao escopo de suas determinações. Este outro locus do comportamento é o meio comportamental (Koffka, 1935/1975). A seguinte citação fornece uma síntese do que, a nosso ver, caracteriza a intencionalidade vital:

\footnotetext{
"Não entendemos aqui por norma um dever ser que faria o ser; é a simples constatação de uma atitude privilegiada, estatisticamente mais frequente, que dá ao comportamento uma unidade de um novo gênero" (Merleau-Ponty, 1942/2006, p. 249).
}

[...] a forma do excitante é criada pelo próprio organismo, por sua maneira peculiar de se oferecer às ações do exterior. Sem dúvida, para poder subsistir, ele deve encontrar um certo número de agentes físicos e químicos. Mas é ele, segundo a natureza de seus centros nervosos, segundo os movimentos dos órgãos, que escolhe no mundo físico os estímulos aos quais será sensível. (Merleau-Ponty, 1942/2006, p. 15)

O conhecimento aplicado sobre a vida, na perspectiva naturalista, não visa à própria vida, mas, antes, direciona-se a processos fisiológicos que, ao invés de constituírem a lei primordial de toda ação, participam do organismo a título de patamares sensíveis, estruturas gerais do comportamento que adquirem sentido apenas se inseridas na dialética que as faz emergir como atividade biológica. Perde-se de vista, na atitude naturalista, o fundo intencional de todo comportamento, o qual consiste, precisamente, na "propriedade que ele [o organismo] tem de estabelecer, por si mesmo, as condições de seu equilíbrio" (Merleau-Ponty, 1942/2006, p. 240). O vivente não busca diminuir o estado de tensão a qualquer custo; o organismo é "unidade de significado", as correlações que este estabelece com seu ambiente não são mediadas por gradientes físicos, são antes "coordenações de sentido" (Merleau-Ponty, 1942/2006, p. 243). A inserção da forma no universo da vida exige que a ciência se depare com o mundo percebido, pelo qual a atividade orgânica aparece como um núcleo sensível de exploração e criação de um mundo circundante (Umwelt).

A apropriação do fundamento estrutural na descrição da ordem vital conduz Merleau-Ponty (1942/2006) a propor uma organização da natureza vivente segundo níveis de integração comportamental. Trata-se de delimitar a experiência vivente a partir das possibilidades de ação inerentes a cada domínio comportamental. Esta estratégia é a maneira pela qual o filósofo evita recair em prejuízos ontológicos que se limitam a explicar a vida através de fatores externos a ela. Há, segundo Merleau-Ponty, diferentes graus de expressão da natureza, a saber, as formas física, vital e espiritual. A noção de forma permite descrever a dimensão vivente como "um modo de ser que somente pode ser conhecido adequadamente a partir de si mesmo" (Bimbenet, 2011/2014, p. 108).

De acordo com a taxonomia de Merleau-Ponty, a classificação das ordens comportamentais compreende três estilos de expressão da vida: as formas sincréticas, as formas amovíveis, e as formas simbólicas. Elas representam níveis diferenciados de assimilação e interpretação das relações com o ambiente circundante, e não simplesmente três gêneros de formas animais. Vislumbra-se, em cada ordem, uma espécie nova de relação com o espaço e o tempo.

No primeiro nível, o sincrético, Merleau-Ponty delimita os comportamentos cujas capacidades de orientação rumo aos aspectos da situação vivida não ultrapassam as normas prescritas pelo instinto. O organismo, neste caso, 
"está aprisionado no quadro de suas condições naturais e não trata as situações inéditas senão como alusões às situações vitais que lhe são prescritas" (Merleau-Ponty, 1942/2006, p. 163). O comportamento de um sapo que persevera em atirar sua língua no vidro de um recipiente, dentro do qual se encontra uma minhoca, é regido por esquemas instintivos que não o permitem uma abstração dos contextos vividos. Por outro lado, observam-se também comportamentos inibitórios, como na situação em que o mesmo animal mastiga um inseto com gosto ruim. De acordo com Merleau-Ponty, a presença de comportamentos aparentemente desprovidos de sentido, como no caso da minhoca, assim como o aparecimento de fenômenos de frenagem, como no caso do inseto, compõe um quadro de condutas prescritas pelas normas vitais do organismo. Não são as "particularidades físicas da situação presente" que delimitam o espectro de condutas possíveis, antes, são "as leis biológicas do comportamento" que orientam a ação. O autor explica: "Devemos chamar instintivo um comportamento que responde literalmente a um complexo de estímulos mais que a certos traços essenciais da situação" (Merleau-Ponty, 1942/2006, p. 164). Neste nível, a aprendizagem pelo condicionamento torna-se um processo duvidoso, visto que a conduta orienta-se segundo determinados a priori estabelecidos pelo aparelho instintivo.

O segundo nível de integração comportamental é representado pela ordem amovível. São observados, nesse patamar, alguns desenvolvimentos de estratégias comportamentais inéditas em relação às do nível anterior. As condutas, nesse caso, não são estritamente determinadas pelo aparelho instintivo, podendo operar conforme aspectos abstratos das situações vividas. As formas amovíveis relacionam-se com determinados sinais, ou categorias, que não são dependentes, stricto sensu, do material visual apresentado. Por exemplo, em experiências de adestramento com galinhas, os animais foram treinados a escolher a cor mais clara entre duas nuances de cinza. Após a cor mais clara ter se tornado reflexógena, o experimentador troca a nuance mais escura por uma ainda mais clara que a primeira. Ao repetir-se o experimento de condicionamento, percebe-se então que o animal escolhe a cor mais clara do novo par de cinzas, e não a nuance antes reflexógena (Merleau-Ponty, 1942/2006, p. 166). Conclui-se disso que o conteúdo aprendido não é tanto um conteúdo, "este cinza”, ou "aquele cinza", mas uma categoria - "mais claro". "O adestramento não introduz no comportamento uma contiguidade de fato. O sinal é uma configuração (Sign-Gestalt)” (Merleau-Ponty, 1942/2006, p. 166).

A capacidade de imitação dos símios antropóides é um exemplo de aprendizagem que não se limita à reprodução automática dos movimentos vistos, mas que emerge do organismo como o poder de conferir uma coesão interna à situação. Analisemos o seguinte relato de pesquisa. Em um experimento com chimpanzés (Köhler, 1929/1957) en- volvendo a manipulação de caixas, um alimento é pendurado no teto de uma jaula. Em um primeiro momento, a visão do objetivo instiga o chimpanzé, e este executa uma série de saltos sem recorrer à caixa. Após muitas horas sem que o animal apresente indícios de resolução do problema, o experimentador posiciona a caixa debaixo do alimento e toca a comida com as mãos. A caixa é, então, deslocada para longe do objetivo e o experimentador deixa a sala. Rapidamente, o animal põe em prática todo o esquema percebido, apoderando-se do alimento. Neste caso, a imitação parece-nos um fenômeno automático, uma espécie de aprendizagem por analogia. Outra situação nos oferece um contraste interessante. Trata-se da observação, também realizada por Köhler, dos comportamentos de um chimpanzé considerado "menos inteligente” em relação aos seus companheiros. A situação era semelhante a do caso anterior. Mesmo atentando-se para as ações dos outros animais, que subiam nas caixas e pegavam os alimentos, este chimpanzé continuava a realizar movimentos inúteis. Sua imitação apenas recortava dos atos totais dos companheiros alguns movimentos, não se constituindo como uma boa forma. Os deslocamentos da caixa eram feitos de modo fortuito, sem relação com o alimento. Conforme as análises de Köhler, para um chimpanzé "inteligente", a caixa e o alimento convergem para um mesmo momento, fazem parte do mesmo ato. Há uma coerência interna entre a percepção da caixa, a percepção do alimento e os movimentos necessários para se alcançar o objetivo. De maneira distinta, no caso do "animal menos inteligente", "ele verá fases isoladas do desempenho todo, não as percebendo como partes relacionadas com a estrutura essencial da situação, como partes da solução" (Köhler, 1929/1978, p. 54)

Estas considerações ilustram, igualmente, a importância de um método descritivo que se atenha aos significados comportamentais que emergem das situações-problema vividas pelo organismo. As comparações clássicas, que identificam o funcionamento animal ao funcionamento de uma máquina, deixam de lado o aspecto circular imanente à relação organismo-meio. Em outras palavras, a constituição de um meio emerge de um processo dialético, que já apresenta o organismo em constante transformação. É mais plausível, portanto, descrever o organismo por meio de uma metáfora musical, a qual permite compreender a atividade como fenômeno de estrutura. "A atividade do organismo seria literalmente comparável a uma melodia cinética, já que toda mudança no fim de uma melodia modifica qualitativamente seu início e a fisionomia do conjunto" (Merleau-Ponty, 1942/2006, p. 168).

Se a intencionalidade vital representa esta capacidade dos organismos vivos de constituir um meio de acordo com significações vitais próprias, que se esboça desde o inicio da escala zoológica, o que pode ser dito em relação ao fenômeno humano? Devemos manter essa espécie de intencionalidade como um aspecto fundante de nosso espaço perceptivo? 


\section{A multiplicidade perspectiva e o fenômeno humano}

O critério de hierarquização da natureza utilizado por Merleau-Ponty não é compatível com a classificação utilizada pela biologia clássica. Para esta última, o parâmetro fundamental de ordenação da natureza consiste em categorizar os fenômenos a partir da distinção entre simples e complexo. Apesar de permanecer em uma esfera de classificação hierárquica, a noção de forma permite a Merleau-Ponty reconhecer a originalidade inerente a cada estrutura de comportamento. A descrição da natureza levada a cabo pela ideia de ordem culmina, necessariamente, no reconhecimento de uma diferença estrutural entre os comportamentos humanos e animais.

As formas simbólicas designam as estruturas de comportamento próprias aos seres humanos. Assim escreve o filósofo: "No comportamento animal os signos permanecem sempre sinais e nunca se tornam símbolos" (Merleau-Ponty, 1942/2006, p. 192). Tomemos o exemplo que inaugura a descrição das formas simbólicas n'A Estrutura do Comportamento. Um cachorro treinado para pular em cadeiras ao comando do adestrador mostra-se incapaz de realizar a tarefa caso as cadeiras sejam substituídas por poltronas, ou banquinhos. De modo inverso, observa-se que esta possibilidade de tematização do signo está na base da aptidão humana em formar hábitos. Toda atividade, ou hábito, exige uma ordenação funcional que está diretamente em sintonia com a tarefa realizada. Segundo Merleau-Ponty, não podemos supor uma construção rígida entre estímulo e movimento que oriente a formação dos hábitos. Um músico, que improvisa em outros instrumentos que não os seus, possui, justamente, uma habilidade passível de ser transposta à nova situação, e não montagens rígidas. É notável o fato de que o hábito emerge como atividade integrada, ou como tematização dos signos locais.

O símbolo, diferente do signo, faz referência a um conjunto de relações, cujo sentido é transponível e independe dos materiais concretos da situação. Perceber, para um ser humano, significa atuar inclusive na esfera do virtual, tangendo não somente os aspectos atuais da situação, mas variando infinitamente seus pontos de vista.

É essa possibilidade de expressões variadas de um mesmo tema, essa "multiplicidade perspectiva" que faltava ao comportamento animal.É ela que introduz uma conduta cognitiva e uma conduta livre. Tornando possíveis todas as substituições e pontos de vista, ela libera os "estímulos" das relações atuais nas quais meu ponto de vista particular os prende, dos valores funcionais que as necessidades da espécie definidas para sempre lhes atribuíam. (Merleau-Ponty, 1942/2006, p. 192)

É sob a insígnia da multiplicidade, da dispersão, do desprendimento sensível, e não da unificação pela razão, que se encontra a percepção humana. Antes de nos aprofundarmos nas implicações antropológicas resultantes do pers- pectivismo, observemos de perto o que significa esta "falta" no comportamento animal, referida na citação acima.

Os fatores que impedem um comportamento sincrético de ascender a uma conduta simbólica tornam-se significativamente visíveis em dois casos experimentais: em tarefas que envolvem o desvio de objetos e em tarefas que envolvem relações estáticas. Em um experimento realizado por Köhler (1929/1957), um dispositivo, similar a uma gaveta, foi instalado do lado de fora da jaula dos chimpanzés, e uma banana foi colocada ali pelo pesquisador. Todos os lados desta gaveta estão fechados, exceto um, o que está diametralmente oposto à jaula. Tendo como instrumento um bastão, a tarefa do chimpanzé consiste em tentar trazer o objeto para si, fazendo com que este realize um desvio. Fazer o objeto realizar o desvio com o bastão é, para o animal, uma tarefa muito mais complexa do que realizar um desvio com o próprio corpo. O cerne da "insuficiência" simbólica de seu comportamento consiste nisto: "o animal não pode se colocar no lugar do objeto e ver a si próprio como o objetivo. Não pode variar os pontos de vista, como não poderia reconhecer uma mesma coisa de diferentes perspectivas" (Merleau-Ponty, 1942/2006, p. 185). A aptidão para se colocar no lugar do objeto, ou no lugar do outro, exige que o espaço vivido, compreendido aqui como a espacialidade concreta e atual, seja substituído pelo desenrolar da ação em um espaço virtual, campo de ações possíveis, e que não estão diretamente relacionadas aos aspectos formais da situação. Verifica-se, igualmente, que a física dos chimpanzés está inteiramente restrita a um ponto de vista auto-centrado. Os chimpanzés são capazes de equilibrar-se em cima de uma pilha de caixas, visto que todo o eixo gravitacional da construção passa a ser regido pelo corpo do animal, mas são incapazes de construir estruturas fisicamente estáveis.

A carência do comportamento animal consiste, portanto, na incapacidade de tratar o objeto como uma coisa, ou seja, como uma "unidade concreta capaz de entrar, sem se perder, numa multiplicidade de relações” (Merleau-Ponty, 1942/2006, p. 185). A alteração do valor funcional do objeto na percepção animal não é vivida como a alteração de uma perspectiva, que manteria preservada a invariância do objeto. A mudança súbita do contexto altera o valor funcional do objeto, derivando-se disso comportamentos que parecem tratar o mesmo objeto como se fossem dois objetos distintos. Por este motivo, Merleau-Ponty afirma que o animal não se utiliza de um instrumento no sentido integral da palavra. Um instrumento comporta uma multiplicidade de usos sob uma estrutura invariável. O galho de árvore utilizado como bastão, comenta Merleau-Ponty, é suprimido, no comportamento do chimpanzé, como galho-de-árvore. $\mathrm{O}$ valor funcional do objeto, que está diretamente ligado à composição total do campo de ação, atua como um verdadeiro "buraco-negro" em relação às outras perspectivas possíveis. Isto é, a função atual suprime as funções precedentes. No comportamento humano, ao contrário, "o galho de árvore transformado em 
bastão continuará justamente um galho-de-árvore-transformado-em-bastão, uma mesma ‘coisa' em duas funções diferentes, visível 'para ele' sob uma pluralidade de aspectos” (Merleau-Ponty, 1942/2006, p. 273).

No regime das formas simbólicas instauram-se, portanto, relações que ultrapassam os valores funcionais dos objetos, e que se dirigem à "estrutura-coisa”. A multiplicidade perspectiva é o emblema de uma percepção propriamente humana. A multiplicidade perspectiva torna possível, mais especificamente, a constituição de um mundo inter-humano, visto que a capacidade de variar os pontos de vista permite a criação de novos meios e a reformulação das estruturas dadas, sejam elas sociais ou naturais. Com efeito, para Merleau-Ponty, a especificidade da ordem humana não consiste em sua capacidade de criar. Trata-se, antes, da capacidade de reinventar, reformular e ultrapassar as estruturas vigentes ${ }^{2}$. Um exemplo simples e patente acerca disso está no fato de que o homem é o único ser que cria instrumentos cuja finalidade é criar outros instrumentos. Para o animal, o objeto é circunscrito pelo círculo de normas vitais e, deste modo, apresenta-se como objeto de interesse apenas em relação à função que assume em um determinado contexto; inversamente, a percepção humana insere-se em um mundo de objetos de uso (Gebrauchs-objekte), cujos valores funcionais não se reduzem às possibilidades dadas pelos $a$ priori monótonos do instinto. Antes, estes objetos de uso são a expressão de uma cultura partilhada. A multiplicidade perspectiva, operante no seio da percepção humana, nos remete, via direta, ao problema da constituição de um mundo comum. Em oposição à subjetivação radical do animal - a particularização de seu ambiente - o perspectivismo humano nos oferece a chave de nossa crença na absolutidade do mundo, na medida em que a visada humana constitui-se, primordialmente, como "intencionalidade compartilhada" (Bimbenet, 2014).

\section{Considerações finais}

Apresentamos uma interpretação da percepção vivente, de acordo com a primeira obra de Merleau-Ponty (1942/2006), à luz do conceito de intencionalidade. Apesar de não encontrarmos em A estrutura do comportamento uma conexão direta entre o termo intencionalidade e a experiência vivente, concluímos que é possível abordar a percepção animal a partir desta noção, desde que esta seja considerada sob o prisma da ideia de Gestalt. Trata-se, portanto, de definir a intencionalidade animal como uma estrutura dinâmica que se direciona ao meio orientada por normas vitais próprias.

\footnotetext{
"O que define o homem não é a capacidade humana de criar. O que define o homem não é a capacidade de criar uma segunda natureza- econômica, social, cultural - para além da natureza biológica, é sobretudo a capacidade de superar as estruturas criadas para criar outras" (Merleau-Ponty, 1942/2006, p. 272).
}

De início, sublinhamos as críticas realizadas por Merleau-Ponty à psicologia científica, a qual define o comportamento a partir de pressupostos deterministas e mecanicistas. Em seguida, mostramos a centralidade do conceito de Gestalt no projeto de redefinição da atividade vivente a partir do seu caráter intencional. Após caracterizarmos a atividade animal como intencional, apresentamos, aо final do artigo, as diferenças principais entre a percepção humana e animal, destacando o lugar ocupado pelo conceito de multiplicidade perspectiva n'A Estrutura do Comportamento.

As teorias científicas do comportamento, à época de Merleau-Ponty, consideram que a conduta pode ser decomposta em elementos reais encontrados no mundo físico. Supõe-se, assim, que o comportamento se origina de uma série de relações causais que desencadeiam, invariavelmente, uma resposta precisa. Merleau-Ponty identifica nesta proposta a exclusão da dimensão intencional da ação. Sob os auspícios da noção de Gestalt, o filósofo empreende o exame das teorias científicas do comportamento tendo em vista superar a visão pela qual o organismo seria um ente passivo e o comportamento um elemento do mundo real. Nesse sentido, de acordo com Merleau-Ponty, a estruturação do campo perceptivo não é um processo que ocorre independentemente do organismo. Deve-se levar em consideração que os fatores funcionais, referentes às capacidades de cada espécie e cada indivíduo, atuam seletivamente na percepção do ambiente, apresentando como objetos de interesse ao organismo apenas aquilo que surge como correlato de suas próprias normas e necessidades vitais. Essa dimensão centralizadora da percepção animal indica que a estruturação de um ambiente próprio é um processo que, necessariamente, implica as demandas do organismo. Este modo de compreender a atividade vivente esquiva-se dos pressupostos vigentes na psicologia científica, e exige que o organismo seja considerado uma totalidade indecomponível cujas ações são irredutíveis a elementos de anatomia ou de fisiologia. Merleau-Ponty refere-se à necessidade de abordarmos a relação organismo/meio em termos dialéticos, o que significa dizer que a realidade biológica é o encontro das estruturas físicas (anatômicas e fisiológicas) e dos aspectos funcionais do organismo servindo na constituição de um meio através de uma atividade normativa.

Convém considerar que estas ideias encontram diversos adeptos em discussões contemporâneas. Observamos, por exemplo, que no cenário atual de pesquisas nas áreas de filosofia fenomenológica e ciências cognitivas, as questões levantadas por Merleau-Ponty em A Estrutura do Comportamento servem como aporte crítico frente ao pensamento objetivista contemporâneo. Alguns autores, como, por exemplo, Varela, Thompson e Rosch (1993), Thompson (2007) e Ellis (2006), recorrem à filosofia de Merleau-Ponty, inclusive ao problema da intencionalidade vivente, com o intuito de criticar os paradigmas representacionalistas da cognição, e ressaltar o papel da 
ação na construção de domínios cognitivos. Este é um dos desdobramentos possíveis de se pensar a atividade vivente pelo viés da intencionalidade. Outro importante representante deste movimento de resgate de temas contidos n'A Estrutura do Comportamento é o filósofo Etienne Bimbenet (2014), cuja obra destaca-se por propor uma fenomenologia da diferença antropológica (a comparação entre comportamentos humanos e animais) assumindo como conceito-chave a ideia de multiplicidade perspectiva, utilizada por Merleau-Ponty para descrever a essência pluralizante do ver humano.

Com efeito, a clarificação da estrutura experiencial vivente remete, diretamente, ao questionamento da estrutura experiencial humana. Ao longo da história da filosofia, as teorias referentes à natureza humana são inteiramente influenciadas pelo modo como se compreendeu a animalidade. Enquanto o animal é, tradicionalmente, considerado uma espécie de autômato, o ser humano, por sua vez, diferencia-se pelo advento da razão. O fenômeno humano surge, nesta lógica, pela justaposição da matéria pensante à matéria corpórea. Para Merleau-Ponty, ao contrário, se a percepção animal não se deixa explicar pela eficácia do estímulo físico atuando em seus receptores, é porque seus processos não são causalmente determinados pelo meio e, portanto, trata-se de uma atividade que, justamente, modula o meio a partir de si. Ao reconhecermos a originalidade das estruturas vitais, torna-se viável tratar o fenômeno humano como uma nova ordem de comportamentos, que congrega aspectos da ordem vital, mas que se diferencia estruturalmente desta. Ao tratarmos da animalidade como uma perspectiva radical sobre o mundo, polarizando o ambiente a partir de seus interesses vitais, subsumindo tudo ao seu próprio ponto de vista, somos conduzidos a definir a racionalidade humana, não mais como a unificação do sentido pela razão, mas, inversamente, como a multiplicação do ver, a virtualização da percepção e, necessariamente, como o encontro com um mundo intersubjetivo.

\section{Referências}

Bimbenet, E. (2004). Nature et Humanité: Le problème Anthropologie dans l'oeuvre de Merleau-Ponty. Paris: Vrin.

Bimbenet, E. (2014). O animal que não sou mais. (M. J. d'Escragnolle Cardoso, Trad.). Curitiba: UFPR.

Buytendijk, F. J.. (1952). Traité de psychologie animale. (A. FrankDusquene, Trad.). Paris: Presses Universitaires de France.

Ellis, R. (2006). Phenomenology-Friendly Neuroscience: The Return To Merleau-Ponty As Psychologist. Human Studies, 29, 33-55.

Ferraz, M. (2009). Fenomenologia e Ontologia em Merleau-Ponty. Campinas: Papirus.

Furlan, R. (2001). A noção de consciência n'A Estrutura do Comportamento (Merleau-Ponty). Psicologia Usp, 12.
Geraets, T. (1971). Vers une nouvelle philosophie transcendantale: La genèse de la philosophie de Maurice Merleau-Ponty jusqu'à la Phénomenologie de la Perception. The Hague: Martinus Nijhoff.

Koffka, K. (1975). Princípios de Psicologia da Gestalt. (Á. Cabral, Trad.). São Paulo: Editora Cultrix, Editora da Universidade de São Paulo. (Trabalho original publicado em 1935)

Köhler, W. (1957). The Mentality of Apes. (E. Winter, Trad.). Nova York: Hartcourt Brace. (Trabalho original publicado em 1929)

Köhler, W. (1968). Psicologia da Gestalt. (D. Jardim, Trad.). Belo Horizonte: Itatiaia. (Trabalho original publicado em 1929)

Köhler, W. (1978). A inteligência dos antropóides. In A. Engelmann (Org.). Wolfgang Köhler (p. 39-56). São Paulo: Ática. (Trabalho original publicado em 1929)

Merleau-Ponty, M. (1984). Em toda e em nenhuma parte. In M. Chauí (Trad.), Merleau-Ponty. Textos Selecionados. São Paulo: Nova Cultural.

Merleau-Ponty, M. (2006). A Estrutura do Comportamento. (M. V. Aguiar, Trad.) (1. ed). São Paulo: Martins Fontes. (Trabalho original publicado em 1942)

Moinat, F. (2012). Le Vivant e sa naturalisation: Le problème du naturalisme en biologie chez Husserl et le jeune Merleau-Ponty. New York: Springer.

Pavlov, I. (1970). A Fisiologia e a Psicopatologia no estudo da atividade nervosa superior dos animais. In U. Uflaker \& E. Andreoli (Trads.), Pavlov: Obras Escolhidas (p. 183-198). São Paulo: Hemus. (Trabalho original publicado em 1917)

Thompson, E. (2007). Mind in Life: Biology, Phenomenology and the Sciences of Mind. Cambridge, Massachusetts: Harvard University Press.

Varela, F., Thompson, E., \& Rosch, E. (1993). The Embodied Mind: Cognitive Science and Human Experience. New York: MIT Press.

Watson, J. (1913). Psychology as the Behaviorist Views it. Psychological Review, 20, 158-177.

Watson, J. (1930). Behaviorism. Londres: Kegan Paul, Trench Trubner and Company.

Pedro Henrique Santos Decanini Marangoni - Doutorando do Programa de Pós-Graduação em Psicologia da Faculdade de Ciências e Letras de Assis - Universidade Estadual Paulista (UNESP), Brasil. Email: pedro.marangoni@yahoo.com.br

Danilo Saretta Verissimo - Docente do Departamento de Psicologia Social e Educacional e do Programa de Pós-Graduação em Psicologia da Faculdade de Ciências e Letras de Assis - Universidade Estadual Paulista (UNESP), Brasil. Endereço Institucional: Av. Dom Antônio, 2100, Parque Universitário, Assis, SP - Brasil. CEP: 19800-000. Email: danilo.verissimo@gmail.com

Recebido em 29.11.2016

Primeira Decisão Editorial em 11.06.2017

Aceito em 02.08.2017 